\title{
GESTÃO DE RECURSOS HUMANOS NO SETOR DE TELECOMUNICAÇÕES: NOVAS EMPRESAS, NOVAS PRÁTICAS?
}

RESUMO

0 objetivo do artigo é discutir as mudanças introduzidas na área de gestão de recursos humanos (GRH) em uma empresa do setor de telecomunicações no período de 1998 a 2003. Foi analisada a GRH após a privatização, fazendo-se um paralelo com as mudanças e inovações incorporadas durante sua reestruturação, até a implantação de um novo modelo de gestão. 0 método utilizado foi o descritivoqualitativo, sendo utilizados, como fonte de dados, depoimentos, análise documental da empresa e levantamento bibliográfico. 0 marco teórico procurou contextualizar as transformações que serviram de pano de fundo para as mudanças ocorridas na empresa. Na organização foi identificado um novo modelo de gestão que evoluiu a partir do modelo praticado em 1998, mas que ainda atua de forma passiva na implementação das mudanças do período.

\section{Cláudia Santos de Castro}

UFMG

ABSTRACT The objective of this article is to discuss the changes introduced in the human resources management of a telecommunications company, from 1998 to 2003. The human resources practices and management were analyzed after the privatization, comparing the changes and innovations incorporated during the period of reorganization until the implementation of a new administration model. The study comprised a research where interviews, analyses and bibliographical searches were used as data sources. The theoretical framework tried to contextualize the transformations that served as background for the changes that occurred in the company. A new administration model was identified in the organization which developed from the 1998 model, but that still works in a passive way in the implementation of changes during the period.

PALAVRAS-CHAVE Organizações, recursos humanos, gestão, competitividade, mudança.

KEYMORDS Organization, human resources, management, competitiveness, change. 


\section{INTRODUÇÃO}

0 intuito deste artigo é descrever e discutir como se processaram as alterações na gestão de recursos humanos em uma empresa de tel ecomunicações que surgiu após o processo de transformações que o setor sofreu na década de 1990. Essa década serviu como expressão concreta de profundas mudanças que se avizinhavam desde os anos 1970. Com efeito, em função dos sucessivos aumentos dos preços do petróleo ocorridos nesta década, as taxas do crescimento econômico sofreram reduções. Elevadas taxas de inflação, aliadas aos déficits crescentes das finanças públicas, provocaram o esgotamento dos recursos financeiros para o setor público. Esse quadro acabou trazendo como conseqüência uma ampla revisão do papel do Estado, evidenciada no Brasil a partir da segunda metade da década de 1990, com a privatização de setores considerados até então prioritários da economia.

Concomitantemente, a década de 1990 evidenciou uma crescente competitividade no mercado mundial. Com a introdução de novas tecnologias e mai ores especializações funcionais, as organizações buscaram maior rapidez para responder às mudanças e às demandas do ambiente, transformando a informação, o conhecimento e a criatividade em um conjunto de recursos considerados estratégicos. Então, tornaram-se necessárias não apenas mudanças tecnológicas, mas, principalmente, novas formas de organização do trabalho, na busca de uma empresa flexível e integrada para elevar a produtividade, fazendo frente a um ambiente marcado pelas incertezas e pela complexidade de mercado (Lopes, 2000).

Essas transformações pelas quais as organizações passaram, e que continuam ocorrendo, apresentam novos desafios no gerenciamento de recursos humanos. Essa situação é observada por Wood Jr. (1995), que trata das mudanças nas condições ambientais e seu impacto sobre a função de recursos humanos, estabelecendo um paralelo entre a visão tradicional e uma perspectiva mais atual.

A abordagem tradicional discutida pelo autor resume a gestão de pessoas como um conjunto de procedimentos de ajuste do indivíduo a um estereótipo de eficiência previamente definido pela empresa. A abordagem aponta que essa área assumiu por muito tempo uma linha de atuação eminentemente técnica, voltada para atividades burocráticas e administrati- vas, como seleção, desenvolvimento de pessoal e treinamento.

Dentro de uma perspectiva atual, o autor observa que a abordagem tradicional, a visão de adequação e obediência da força de trabal ho aos objetivos organizacionais, é substituída por uma gestão de recursos humanos ( $\mathrm{GHH}$ ) focada no comprometimento de RH com os objetivos organizacionais. Isso significa dizer que a GRH passa a considerar o fator humano como aspecto-chave para o sucesso organizacional, apresentando uma preocupação em alinhar suas ações às estratégias da empresa.

Nessa perspectiva, o novo modelo de gestão de pessoas e as relações internas que estimula são, ao que tudo indica, reflexos daquilo que vem ocorrendo com a sociedade. Tal posicionamento pode ser comprovado pela preocupação em desenvolver, ainda que em menor volume e de forma "atropelada" - como ressalta Wood Jr. (1995) -, tarefas não rotineiras, de caráter mais amplo, intensificando a preocupação com os objetivos organizacionais. Conforme descreve Ulrich (1998, p. 66), "surge a necessidade dos profissionais de $\mathrm{RH}$ equilibrarem esse processo de mudança, inovação e transformação, com objetivos de continuidade, disciplina e estabilidade".

É nesse quadro que se insere a proposta deste trabalho. Ele analisa a trajetória da GRH em uma empresa de telecomunicações surgida após 1998, ano de sua privatização, até 2003. Em junho de 1998 foi publicado o edital de venda da Empresa de Telecomunicações Brasileiras S.A. (Telebrás), que foi dividida em 12 holdings, sendo três empresas de telefonia fixa local e intra-estadual, oito de tel efonia móvel e uma, a Embratel, de tel efonia de longa distância (interurbanos nacionais, internacionais e interestaduais). Entre as três holdings de telefonia fixa estava a Tele N orte-Leste, atual Telemar, formada pela fusão de 16 operadoras das regiões N orte, N ordeste e Sudeste do país que passaram a ser controladas pelo grupo Tele Norte-Leste Participações S/A. Após a privatização, essa empresa iniciou um processo de reestruturação empresarial. Todas as ações desse processo tinham como visão transformar a Telemar na maior empresa de telecomunicações da América Latina até 2008. O bjetivava atingir essas metas por meio das pessoas, ou seja, al cançar resultados por meio de uma melhor gestão de pessoas. Conseqüentemente, ocorreram mudanças na GRH que foram analisadas neste artigo em três momentos: pós-privatização, reconstrução e novo modelo. 


\section{REFERENCIAL TEÓRICO}

\section{Papel do Estado e as bases da privatização do setor de telecomunicações}

0 padrão de acumulação capitalista que perdurou após a Segunda Guerra Mundial até o início da década de 1970 foi um período no qual esse sistema conviveu com elevadas taxas de crescimento, apesar da tensão política gerada entre os dois grandes blocos liderados pela extinta U nião Soviética e pelos Estados Unidos, e que recebeu a denominação de guerra fria. A sistemática de produção em massa e o Welfare State começaram a mostrar sinais de esgotamento. Aos poucos, instaurou-se uma situação caracterizada pela estagflação, ${ }^{1}$ pela instabilidade financeira e pela queda de produtividade agravada pela crise do petróleo em dois momentos distintos: em 1973, quando ocorreu o primeiro choque do petróleo, e no final da década de 1970, com o segundo choque. Diante desse cenário, fatores como a saturação do mercado de bens duráveis, a perda do poder aquisitivo de grande parte da população, a entrada de novos países produtores e a formação de blocos regionais levaram as empresas a repensar sua forma organizacional.

No âmbito do Estado, o seu novo perfil de atuação se pautou por procurar facilitar a inserção empresarial no ambiente internacional de forma competitiva, ao mesmo tempo em que limitava sua atuação em determinados setores, ganhando corpo a idéia de Estado mínimo. Torna-se desnecessário lembrar que essa idéia, na verdade, correspondeu a uma nova visão internacional, em que o Estado desempenharia somente tarefas como a segurança pública, a distribuição da justiça e a manutenção do equilíbrio social, entre outras atividades peculiares e intransferíveis. Essa configuração seria alcançada via privatização, entendida por Savas (1990, p. 13) como "o ato de reduzir o papel do governo, ou de dar maior importância ao setor privado, numa atividade ou na propriedade de bens".

No Brasil, os anos 1980 e início da década de 1990 marcaram um período de significativa estagnação nos investimentos estatais no sistema de telecomunicações. 0 sistema Telebrás foi uma das primeiras áreas estatais a ter seus investimentos restringidos. Segundo Brandão (1996), os resultados dos baixos níveis de investimentos, acompanhados de uma progressiva burocratização no sistema, foram mais acentuados do que em outros setores. No início de 1990, a situação do setor de telecomunicações brasileiro era considerada precária, pois a sua pequena dimensão ocasionava uma enorme demanda reprimida, acompanhada de desequilíbrios regionais nas instalações de terminais e uma enorme carência de investimentos que viabilizassem o desenvolvimento tecnológico e dos serviços.

De acordo com Luz (2001), a partir de 1996 iniciou-se a reestruturação do setor de telecomunicações brasileiro com a aprovação da Lei Geral das Telecomunicações e a constituição do arcabouço regulatório seguido do processo de privatização do sistema Telebrás, que ocorreu em 29 de julho de 1998 em um leilão na Bolsa de Valores do Rio de Janeiro. 0 governo federal vendeu 12 holdings, criadas a partir da cisão do sistema Telebrás, representando a transferência à iniciativa privada das empresas de telefonia fixa e de longa distância, bem como das empresas de tel efonia celular.

Entre as holdings de telefonia fixa estavam a Tele Centro-Sul (Distrito Federal e estados do Rio Grande do Sul, Santa Catarina, Paraná, M ato Grosso do Sul, Mato Grosso, Goiás, Tocantins, Rondônia e Acre), a Telesp (estado de São Paulo) e a Tele N orte-Leste (regiões Sudeste, Nordeste, estados do Pará, Amapá, Amazonas e Roraima). A Tele Norte-Leste foi transformada em Telemar em abril de 1999. A área de atuação da Telemar corresponde a $64 \%$ do território nacional e oferece serviços de telefonia fixa em 16 estados: na Região Sudeste, exceto São Paulo (Rio de Janeiro, Minas Gerais e Espírito Santo), nas regiões Norte (exceto Acre, Tocantins e Rondônia) e N ordeste, além da regional São Paulo que engloba o Distrito Federal. A área de concessão chega a 5,4 milhões de quilômetros quadrados, englobando mais de 92 milhões de pessoas, o equivalente a $54 \%$ da população ( $L u z$, 2001). Simultaneamente a esse processo de rearranjo produtivo que possibilitou o surgimento de uma nova empresa de telefonia no setor de telecomunicações brasileiro, é realizada uma reflexão acerca da gestão de recursos humanos no setor de telecomunicações pós-privatização, observando-se o seu impacto na gestão de recursos humanos na dimensão macro e seu desdobramento nas práticas gerenciais.

\section{Impactos na gestão de recursos humanos e o contexto contemporâneo}

A lógica da gestão de recursos humanos sofreu modificações nestes últimos anos, crescendo em importância e complexidade. Isso especialmente em virtude de sua condição intrínseca mediadora das relações 
de trabalho, seja na comunicação da cultura da empresa ou na elaboração das políticas e diretrizes que conduzem o trabal ho dos empregados para a consecução dos objetivos organizacionais.

$\mathrm{N}$ a realidade cotidiana das organizações, fazer cortes de pessoal é uma prática comum, porém delicada e que poucos comentam abertamente. Desde os anos 1980 vive-se uma onda crescente e extraordinária de enxugamentos no mundo empresarial, e novas pesquisas passaram a relacionar enxugamentos com downsizing, quando muitas empresas de renomado desempenho passaram a enxugar pessoal de forma quase permanente ( $C$ aldas, 1998). Segundo Fischer (1998), a segunda mudança que atingiu a área de RH foi similar à que atingiu as demais áreas da empresa, ou seja, a descentralização de suas funções e a conseqüente perda do poder de monopólio no atendimento às áreas fins.

Por meio de uma tipologia adotada por Fischer (1998), diversos autores discutem ou apresentam importantes contribuições no estudo evolutivo da gestão de recursos humanos. Podem ser considerados Albuquerque (1987), Fleury (1993), Fleury e Fleury
(1995), Wood Jr. (1995), Burke (1997) e Melo (1997). Para efeito deste trabalho, considerou-se de maneira objetiva que as contribuições dos diferentes autores podem ser agrupadas a partir do estudo de Fischer (1998), que serve como base descritiva desse quadro. 0 Quadro 1 descreve as abordagens e perspectivas de acordo com esse autor.

Emergindo do que poderíamos chamar de uma crise de identidade, a literatura indica que gradativamente parece vir se constituindo um novo modelo de gestão que, como um fenômeno organizacional em formação, não pode ser totalmente circunscrito. Não é possível detalhar todos os seus componentes, mas seguramente é possível delinear suas tendências principais, verificando como se manifestam em algumas organizações ou setores de atividade (Fischer, 1998). Esse modelo competitivo ou de gestão de pessoas aparece em organizações cujo desempenho humano é uma fonte diferencial para o negócio. A pesar de se manifestar de forma bastante diferenciada entre empresas e setores, o model o apresenta algumas tendências gerais que são relativamente homogêneas e identificáveis.

Quadro 1 - Gestão de recursos humanos: abordagens e perspectivas evolutivas.

ABORDAGENS

Administração de Recursos Humanos como

Gestão de Pessoal

Administração de Recursos Humanos como Gestão do Comportamento

Administração de Recursos Humanos como Gestão Estratégica

Administração de Recursos Humanos como Vantagem Competitiva

\section{PRINCIPAIS TÓPICOS}

Empregado como fator de produção

$\mathrm{RH}$ ocupa posicionamento passivo e dependente

RH voltado para a eficiência de custos

RH busca trabalhadores adequados às tarefas cientificamente ordenadas

Relação entre empresa e pessoas é intermediada pelos gerentes de linha

Treinamento gerencial

Relações interpessoais

Processo de avaliação e desempenho

Embrionária valorização dos processos de desenvolvimento de pessoas

Comprometimento dos empregados

Flexibilidade

0 papel de RH se resume a adaptar-se a estratégia do negócio e implementar sua diretriz específica

Não é levada em consideração a possibilidade da administração de recursos humanos intervir na estratégia corporativa

A principal responsabilidade de RH é integrar harmoniosamente as áreas da empresa

0 ser humano é visto e tratado como fonte de vantagem competitiva 
Fischer (1998) e Ulrich (1997) descrevem algumas tendências da GRH que caracterizam este novo modelo. Para esses autores, RH se concentraria nos resultados que ela pode agregar aos seus clientes por meio de produtos e serviços. O papel da teoria da GRH passa a se concentrar em explicar o porquê da necessidade de usar determinadas práticas ou padrões e não se limita a recomendações de melhores práticas, como no modelo da antiga abordagem.

Fischer (1998) definiu as tendências que considerou mais coerentes com o novo modelo de gestão em formação no Brasil. 0 autor propõe organizá-las em um conjunto de cinco categorias classificatórias, as quais são definidas de acordo com os tipos de mudanças indicados pelas tendências:

- Tendências quanto ao foco ou papel principal do modelo de gestão de pessoas: estar em permanente interação com a estratégia do negócio da empresa, interferindo na sua definição e disseminação; integrar os objetivos dos processos de $\mathrm{RH}$ aos objetivos de negócio; focar resultados explicitamente reconhecidos por seus clientes internos e externos como um valor agregado; e atuar, predominantemente, como um órgão gestor de informações;

- Tendências quanto à estrutura e forma de atuação: uma estrutura flexível, organizada em células, redes e equipes que se distribuem em processos e clientes; contingente pequeno de profissionais altamente capacitados realizando atividades com muita inteligência agregada; e terceirização das atividades operacionais, que implica uma relação intensa, atual ização permanente e conhecimento profundo do mercado externo da GRH;

- Tendências quanto ao papel dos profissionais de $\mathrm{RH}$ : consultores internos polivalentes e multidisciplinares; agentes de disseminação estratégica; familiaridade com outras disciplinas da administração, al ém daquelas relacionadas com o comportamento humano; habilidades de aconselhamento pessoal e profissional para atuar como parceiros dos funcionários no planejamento individual de suas carreiras; e ações de desenvolvimento e domínio de metodologias de desenvolvimento, adaptação e interiorização de produtos e processos;

- Orientação dos processos de recursos humanos: integrados entre si, de tal maneira que haja coerência entre os procedimentos e as ferramentas adotadas; orientação prioritária para o desenvolvimento como elemento integrador, para fazer frente a um ambiente organizacional em constante mudança, em que os desafios organizacionais vão se sucedendo; e processos integrados à estratégia de negócios, o que define o caráter competitivo não só para o modelo, mas para cada um de seus processos;

- Tendências de remodelação de cada um dos processos: considera-se importante destacar as tendências mais relevantes para al guns dos processos de gestão porque elas exemplificam como as políticas se transformam em ações práticas nas organizações: relações sindicais - diminuem de importância; captação - administrar o relacionamento com fontes de captação, gerir informações sobre o mercado de trabalho; remuneração - administrar terceiros prestadores de serviços para minimizar salários fixos, segmentação das políticas e práticas salariais, flexibilização da remuneração vinculando-a a padrões de desempenho e competência; desenvolvimento - estímulo ao autodesenvolvimento, criação a um ambiente propício à aprendizagem, ferramentas tradicionais de RH ganham foco em desenvolvimento (avaliação de desempenho, pesquisas de clima organizacional, gestão de carreiras).

Ocorre uma diminuição da importância relativa na negociação sindical como um processo dentro de RH. A crise de desemprego estrutural, a descentralização das grandes empresas para áreas sem tradição sindical e a própria mudança no perfil de atuação das empresas e dos sindicatos diminuem a ênfase das relações sindicais como uma preocupação específica do modelo da GRH.

Diante do arcabouço teórico analisado, pode-se afirmar que as mudanças no contexto socioeconômico brasileiro levaram a uma redefinição do papel do Estado. N esse sentido, organizações públicas - como as do setor de telecomunicações - foram privatizadas e inseridas no mercado, ocasionando a reestruturação e criação de um novo modelo de gestão. Tal fato impactou a gestão de recursos humanos, que vem se adaptando e crescendo em importância, na medida em que fortal ece sua relação com a estratégia da empresa, e voltando-se para a geração de resultados.

À luz do quadro traçado e considerando o contexto produtivo, que encontrou uma profunda reformulação na lógica de atuação das empresas públicas, no controle econômico e na mudança de perspectiva na gestão de pessoas, foi desenvolvido um estudo que abor- 
da a empresa Telemar, criada após o processo de privatização brasileiro no setor de telecomunicações.

\section{PROCEDIMENTOS METODOLÓGICOS}

A pesquisa abordou a empresa de telecomunicações Telemar. Essa empresa atua numa área que abrange os estados de Rio de Janeiro, Minas Gerais, Espírito Santo, Bahia, Sergipe, Alagoas, Pernambuco, Paraíba, Rio Grande do N orte, Piauí, Ceará, Maranhão, Pará, Amazonas, Amapá e Roraima, que juntos representam $64 \%$ do território nacional, geram mais de US\$ 300 bilhões do PIB e possuem uma população de 87 milhões de pessoas (Telemar, 2003).

A estratégia de pesquisa utilizada foi o estudo de caso, considerada a mais adequada para os objetivos deste trabalho porque, como afirmam Goode e Hatt (1960, p. 423), essa estratégia "é um meio de se organizar os dados, preservando o caráter unitário do objeto social estudado [...] uma técnica que considera qualquer unidade social como um todo". Segundo Greenwood (1973), o propósito fundamental do estudo de caso é anal isar intensivamente uma dada unidade social por meio de um exame intensivo de uma unidade de análise.

Nessa perspectiva, realizou-se um estudo de natureza descritiva e qualitativa. Conforme De Bruyne, Herman e De Schoutheete (1997, p. 225), "os estudos de caso tipo descritivo têm como propósito descrever toda a complexidade de um caso concreto sem absolutamente pretender obter o geral". 0 estudo apresentou caráter qual itati vo porque, conforme afirma Godoy (1995), ao referir-se aos aspectos que caracterizam estudos dessa natureza, procurou obter dados descritivos de uma empresa a partir do contato direto do pesquisador com a situação estudada e de sua intenção de compreender os fenômenos a ela relacionados. Para operacionalizar essa escolha do método, os instrumentos de coleta de dados utilizados foram entrevistas semi-estruturadas e análise documental.
0 roteiro foi elaborado de acordo com as categorias de tendências propostas por Fischer (1998): foco ou papel principal do modelo de gestão de pessoas, estrutura e forma de atuação, papel dos profissionais de $\mathrm{RH}$, orientação dos processos de $\mathrm{GRH}$ e remodelação dos processos. Foram realizadas 17 entrevistas com os profissionais da empresa que atuam na área de $\mathrm{RH}$ da matriz e das regionais (totalizando 98 profissionais), englobando todos os profissionais dos cargos de gerência e diretoria da empresa. Foi entrevistado um representante da direção do sindicato dos trabal hadores para discutir as práticas da empresa, sendo essa entrevista utilizada como elemento complementar da análise de resultados.

\section{ANÁLISE DOS RESULTADOS}

A partir dos resultados encontrados no levantamento, é possível tecer uma análise da trajetória de RH no período estudado. 0 processo de mudança do modelo de gestão de pessoas na Tel emar passou por três fases. $\mathrm{Na}$ primeira, o setor de $\mathrm{RH}$ se limitou a fazer o papel de "apagador de incêndio", cuja prioridade foi unir as 16 empresas em apenas uma, por conta da reestruturação do grupo. N esse momento, o RH se restringiu às funções operacionais desenvolvidas antes da privatização.

Em meados de 1999 foi iniciada a segunda fase. A Telemar contratou uma empresa de consultoria, e iniciou-se a reestruturação da organização e, conseqüentemente, das práticas adotadas pelo RH. Essas práticas foram questionadas porque 0 que era praticado anteriormente não estava adequado às mudanças globais introduzidas. Entre outras mudanças, criou-se a gerência de gestão pela qual o RH aproximou-se da estratégia do negócio, possibilitando o início da interação entre a estratégia do RH e a estratégia global da empresa. Essa mudança gerou a necessidade de adequação das antigas práticas ao novo contexto, já que o RH passou a atuar como área de apoio para a geração de resultados. As antigas práticas foram substituídas,

Figura 1 - Mudanças na gestão de Recursos Humanos de 1998 a 2003.

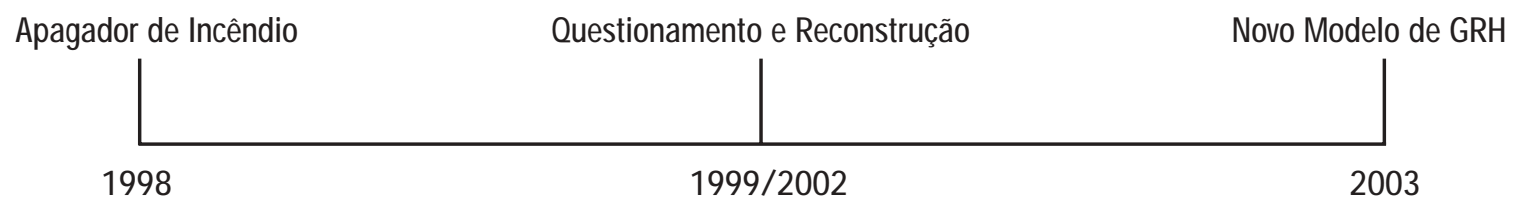


abandonadas ou tornaram-se meramente burocráticas, e novas ferramentas foram criadas para dar suporte às novas necessidades e responsabilidades do $\mathrm{RH}$.

$\mathrm{N}$ a terceira fase, o novo modelo de gestão do $\mathrm{RH}$ estabelecido em novas bases, incorporando as mudanças propostas pela empresa de consultoria - passa a demandar ações específicas de atuação. A área continua suas atividades isoladamente e incorporando as mudanças introduzidas. Concomitantemente, o RH começa a desenvolver sua forma particular de gestão, propondo e desenvolvendo novos produtos e serviços mediante as necessidades da organização. A Figura 1 registra as mudanças na gestão de Recursos Humanos no período de 1998 a 2003.

Em 1998 a empresa era composta por 16 operadoras, e existiam 16 áreas de Recursos Humanos independentes. A estrutura de RH era composta pelas gerências de treinamento, benefícios, assistência médica e de pessoal. Em 1999 surgiu a matriz no Rio de Janeiro e quatro regionais: Minas Gerais, Bahia, Pernambuco e Ceará. N esse momento, a matriz centralizou as gerências de remuneração, relações trabaIhistas e benefícios, comunicação interna, gestão empresarial e desenvolvimento. As regionais passaram a atuar de acordo com diretrizes definidas na matriz na tentativa de uniformizar a gestão na empresa. Em 2003 foi criada uma nova estrutura, com três gerências regionais de recursos humanos - NNE, RMG e RRJ -, incorporada pela matriz, além de uma gerência situada em São Paulo para a prestação de serviços a grandes corporações. As gerências de remuneração, relações trabal histas e ben efícios, comunicação interna, gestão empresarial e desenvolvimento continuaram centralizadas na matriz. A centralização da GRH, perante as regionais, deixa em segundo plano as peculiaridades e regionalidades dessas filiais, pois todos os processos passaram a ser criados e implementados de forma padronizada em todo o país.

Diante dessa reestruturação da área de $\mathrm{RH}$, observouse uma diminuição de sua estrutura. Esse fato contrapõe-se ao discurso da organização de ser a maior empresa de telecomunicações da América Latina, mas reafirma o exposto por Caldas (1998) ao relatar a prática de cortes de pessoal como uma realidade cotidiana das organizações. Não foi possível obter o número total de pessoas que trabalhavam na GRH antes da privatização. Sabe-se que cada operadora possuía seu RH independente. Hoje existem 98 funcionários na organização, sendo que 26 trabalham na matriz (Rio de Janeiro), onde todos os processos são desenvolvidos.
A criação da gerência de gestão empresarial permitiu um melhor ajustamento entre as políticas e práticas de RH ao planejamento estratégico da empresa. Por meio dessa gerência o RH passou a atuar diretamente nas áreas, levantando as necessidades e entregando produtos e serviços por meio da figura do consultor interno de RH. O consultor desenvolve as políticas de RH em todas as áreas da organização. Essa atividade permite a esse profissional um conhecimento geral do negócio, fazendo dele um elo de ligação entre o RH e as outras áreas da empresa. As políticas e práticas são desenvolvidas com cada um dos gestores na busca de padronização das atividades e assimilação dos processos. De acordo com Fischer (1998), essa é uma tendência de mudança no papel dos profissionais de $\mathrm{RH}$ nas organizações, setor que tende a se tornar polivalente e multidisciplinar.

Para melhorar a comunicação interna na organização foi criada a gerência de comunicação interna, que possibilitou um melhor fluxo de informações na empresa. Essa gerência contribui para a unificação da cultura Tel emar, na medida em que trabal ha como órgão gestor de informações e difunde os valores organizacionais. Suas ações permitem alinhar os empregados em relação às diretrizes, metas e modelo de gestão corporativo.

O planejamento e a gestão de carreira não são processos definidos pela empresa. Esses são de responsabilidade do empregado que busca oportunidades de ascensão na empresa. 0 que existe é promoção por reconhecimento interno de seus gestores sem uma definição formal. N esse sentido, um processo de carreira definido poderia melhorar o clima frente às constantes demissões, gerando convergência entre os interesses dos funcionários e da empresa.

Algumas atividades de $\mathrm{RH}$ foram terceirizadas, como recrutamento, seleção, treinamento, mas al guns processos ainda são realizados pela empresa. A geração de folha de pagamentos, benefícios e férias são processos exclusivos da matriz, confrontando-se com a tendência relatada por Fischer (1998) de terceirização de processos operacionais.

A ordenação de trabalho em equipe também se mostrou disseminada na organização com o objetivo de resolver problemas que requerem maiores esforços, como o gerenciamento por projetos, com o auxilio de ferramentas de trabalho como o Seis Sigma (black belts ${ }^{3}$ e green belts ${ }^{4}$ ). Esse fato permite à empresa concentrar os melhores profissionais para resolver problemas específicos utilizando ferramentas 
que proporcionam a resolução de problemas que não seriam solucionados por vias normais de procedimento. Segundo o referencial teórico, essa estrutura flexível organizada em processos permite a formação de um contingente de profissionais al tamente capacitados para a realização das atividades com inteligência agregada.

O novo modelo prevê um profissional que desenvolva novas metodologias com adaptação e interiorização de novos produtos e processos. Embora seja essa a tendência, o profissional de $\mathrm{RH}$ ainda está limitado à implantação de metodologias desenvolvidas pela empresa de consultoria, mas sua evolução é considerável perante o profissional operacional que atuava em 1998.

A flexibilidade da remuneração por desempenho está vinculada a metas estabel ecidas. 0 cumprimento dessas metas proporciona, do cargo de presidente até 0 de coordenador, 0 alcance do bônus executivo, que pode chegar ao pagamento anual de até 30 salários adicionais do cargo, dependendo do grau de dificuldade. Essa medida gera maior comprometimento desses funcionários e faz com que eles exijam resultados de seus subordinados. Conseqüentemente, aumentam o lucro da empresa e a motivação dos funcionários.

Em 1998 a empresa teve sérios problemas nas relações com o sindicato. 0 processo de demissão após a privatização acarretou descontentamento dos em- pregados e do sindicato, mas foi in evitável para a reestruturação na busca da eficiência. Hoje, busca-se um aprimoramento no relacionamento entre sindicato, empresa e funcionários, mas a conciliação de objetivos ainda é por vezes conflitante. A pós a privatização, o poder do sindicato diminuiu nas negociações com a empresa. Isso fortalece a tendência analisada por Fischer (1998) da diminuição de importância da negociação sindical entre os processos de RH. O Quadro 2 sintetiza as principais mudanças na gestão de Recursos Humanos, no período de 1998 a 2003.

0 novo modelo da GRH permite sua participação nas decisões estratégicas do negócio da empresa via comitê formado pelo presidente e por seus diretores relacionados a pessoas, qualidade, investimento, tecnologia da informação e interconexão. $\mathrm{O}$ RH é suporte para cumprimento do planejamento estratégico da empresa visando gerar resultados por meio das pessoas.

\section{CONSIDERAÇÕES FINAIS}

A intensificação da competitividade empresarial devida à globalização e as mudanças no perfil da sociedade brasileira ocorridas na ultima década geraram um novo padrão de gestão de pessoas, diferente do praticado até então nas organizações do país. 0 processo de privatização exigiu a reestruturação das

Quadro 2 - Síntese das mudanças na gestão de Recursos Humanos de 1998 a 2003.

\begin{tabular}{|c|c|}
\hline \multicolumn{2}{|r|}{1998 - APAGADOR DE INCÊNDIOS } \\
\hline PERIODO & MUDANÇAS NA GESTÃO DE RECURSOS HUMANOS (1998 - 2003) \\
\hline $\begin{array}{l}\text { Foco ou Papel } \\
\text { Principal do Modelo }\end{array}$ & $\begin{array}{l}\text { - Foco da GRH voltado para realização de atividades burocráticas e operacionais como: folha de paga- } \\
\text { mento, pagamento de férias, décimo terceiro e atividades de treinamento }\end{array}$ \\
\hline Estrutura & $\begin{array}{l}\text { - Estrutura inchada e centralizada em cada operadora } \\
\text { - As } 16 \text { operadoras possuíam certa liberdade para o gerenciamento de RH }\end{array}$ \\
\hline $\begin{array}{l}\text { Papel dos } \\
\text { Profissionais de RH }\end{array}$ & $\begin{array}{l}\text { - GRH não interligada com a estratégia do negócio. Suas atividades estavam vinculadas a atividades } \\
\text { operacionais e burocráticas da empresa }\end{array}$ \\
\hline Processos & $\begin{array}{l}\text { - Remuneração vinculada a tempo de serviço } \\
\text { - Treinamento desligado da necessidade do negócio da empresa. Esse processo era relacionado à ativi- } \\
\text { dade da área onde o profissional estava alocado } \\
\text { - Atividades operacionais }\end{array}$ \\
\hline
\end{tabular}




\begin{tabular}{|c|c|}
\hline \multicolumn{2}{|r|}{1999 - 2002 - QUESTIONAMENTO E RECONSTRUÇÃO } \\
\hline PERIOODO & MUDANÇAS NA GESTÃO DE RECURSOS HUMANOS (1998 - 2003) \\
\hline $\begin{array}{l}\text { Foco ou Papel } \\
\text { Principal do Modelo }\end{array}$ & $\begin{array}{l}\text { - Construção do novo modelo de gestão com ajuda de uma empresa de consultoria contratada em } \\
\text { meados de } 1999 \\
\text { - Órgão gestor de informaçães através da gerência de comunicação interna } \\
\text { - Participação nas decisões estratégicas do negócio da empresa via comitê formado pelo presiden- } \\
\text { te e seus diretores relacionados a pessoas, qualidade, investimento, tecnologia da informação e } \\
\text { interconexão }\end{array}$ \\
\hline Estrutura & $\begin{array}{l}\text { - Terceirização de atividades operacionais } \\
\text { - Surgimento da matriz no Rio de Janeiro e quatro regionais: Minas Gerais, Bahia, Pernambuco e } \\
\text { Ceará } \\
\text { - Criação de equipes para resolução de trabalhos que exigem conhecimento profundo de determinado } \\
\text { assunto e atuação dos consultores internos que entregam produtos e recebem demandas de todas as } \\
\text { áreas da empresa }\end{array}$ \\
\hline $\begin{array}{l}\text { Papel dos } \\
\text { Profissionais de RH }\end{array}$ & $\begin{array}{l}\text { - Desenvolvimento de consultores internos polivalentes e multidisciplinares } \\
\text { - Desenvolvimento de profissionais com conhecimento profundo do negócio da empresa com familiari- } \\
\text { dade com outras disciplinas da administração e atuação no negócio através do modelo de gestão }\end{array}$ \\
\hline Processos & $\begin{array}{l}\text { - Remuneração adaptada às faixas salariais, usando a metodologia Hay, adotada pela empresa de } \\
\text { consultoria } \\
\text { - Ganha especial ênfase o processo de desenvolvimento a longo prazo, via academia de liderança, } \\
\text { que é um programa cujo principal objetivo é desenvolver as competências de liderança dos gestores } \\
\text { da empresa } \\
\text { - Incorporação de programas externos de desenvolvimento e de novas ferramentas (Seis Sigma, } \\
\text { Gerenciamento de Projetos) } \\
\text { - Recrutamento e seleção realizado por consultores externos a organização }\end{array}$ \\
\hline \multicolumn{2}{|r|}{2003 - NOVO MODELO DE GRH } \\
\hline PERIODO & MUDANÇAS NA GESTÃO DE RECURSOS HUMANOS (1998 - 2003) \\
\hline $\begin{array}{l}\text { Foco ou Papel } \\
\text { Principal do Modelo }\end{array}$ & - RH agente de disseminação estratégica \\
\hline Estrutura & $\begin{array}{l}\text { - Nova estrutura com a matriz no Rio de Janeiro e as regionais NNE, RMG e RRJ, que é incorporada pela } \\
\text { matriz } \\
\text { - Centralização na matriz, onde são desenvolvidos todos os processos de gestão implementados nas } \\
\text { regionais via gerente e coordenador da área de RH }\end{array}$ \\
\hline $\begin{array}{l}\text { Papel dos } \\
\text { Profissionais de RH }\end{array}$ & $\begin{array}{l}\text { Domínio de metodologia de desenvolvimento, adaptação e internalização de produtos e processos e } \\
\text { adaptação da fase anterior }\end{array}$ \\
\hline Processos & $\begin{array}{l}\text { - Flexibilização da remuneração vinculando-a a padrões de desempenho } \\
\text { - Treinamentos vinculados diretamente à estratégia do negócio da empresa via gerência de gestão e do } \\
\text { trabalho dos consultores internos } \\
\text { - Continuação do desenvolvimento das práticas implantadas a partir de } 1999\end{array}$ \\
\hline
\end{tabular}


empresas, visto que as práticas e políticas utilizadas anteriormente não eram mais adequadas ao novo ambiente, marcado pelas constantes mudanças de contexto. Diante de tais mudanças, tornou-se evidente a necessidade de implantar nas organizações um novo modelo de gestão de $\mathrm{RH}$, que deixasse de citar regras e teorias prescritivas, portanto um modelo mais amplo, em que cada empresa fosse capaz de desenvolver seu próprio modo de gestão. No estudo de caso real izado, observou-se uma tendência à importação de práticas e políticas do mercado via empresa de consultoria. $\mathrm{O} \mathrm{RH}$ não foi responsável pelas mudanças em nenhum momento, e a área foi adaptada ao novo contexto diante do processo de reestruturação empresarial.

Verificou-se que a formação do novo modelo resultou de ajustes da empresa ao ambiente, ou seja, às modificações que ocorreram noutras instâncias da organização e que exigem novas políticas e práticas de gestão de pessoas. A mudança foi resultado do ambiente externo e evidencia o caráter dependente da gestão de recursos humanos em rel ação às al terações globais vividas pela organização. Todas as mudanças introduzidas na empresa tiveram como foco prioritário a conquista de uma posição favorável no mercado, com padrões internacionais de qualidade e produtividade, além da redução de custos, os quais foram os principais objetivos das reformulações empresariais da década de 1990.

No primeiro período após a privatização, não houve grandes mudanças na operacionalização das atividades desenvolvidas pela Telebrás em busca de uma futura reestruturação. Numa segunda etapa, foram iniciadas transformações organizacionais por meio de uma empresa de consultoria contratada para reestruturar e implantar processos para o desenvolvimento da organização. O RH foi nada mais que uma das áreas reestruturadas e que se adaptou ao processo. Num terceiro estágio, as políticas e processos de RH foram se adaptando à nova estratégia implantada, porém de forma articulada para que a área passasse a entender do negócio da empresa e se tornasse um parceiro estratégico voltado para os resultados da organização. O RH foi preparado para atuar em parceira, começando por refletir criticamente sobre a sua própria atuação ao longo do processo, para que o modelo de gestão implantado obtivesse maiores chances de se articular internamente e se orientar por políticas coerentes com as mudanças organizacionais mais amplas.
A função Recursos Humanos tornou-se estratégi$\mathrm{ca}$, pois o RH passou a desenvolver suas atividades vinculadas diretamente à estratégia do negócio. Suas atividades foram interligadas às diretrizes estabelecidas pelos acionistas, e o RH - que na época da Telebrás ocupava-se basicamente de processos operacionais - passou a intervir via comitê na estratégia do negócio visando gerar resultados para a empresa.

Nesse novo quadro, o RH poderia estar formulando produtos e serviços. Entretanto, ele se limita a atender às demandas das áreas da organização. Considerando-se as mudanças em fase inicial, espera-se, a longo prazo, que a nova GRH dissemine a estratégia da empresa e saiba agir como estimuladora de processos de mudança organizacional. 0 foco da GRH passa a ser gerar resultados por meio das pessoas e ser reconhecido por seus clientes internos e externos como agregador de valor.

As ações de RH até 2002 foram desenvolvidas por empresas de consultoria. Isso foi necessário diante da impossibilidade de 0 antigo RH realizar as mudanças, devido à limitação da área e por não possuir os conhecimentos necessários. Mas para que a área alcance resultados melhores é preciso aprender a se autodesenvolver, identificando e desenvolvendo produtos que viabilizem a realização do cumprimento do planejamento estratégico da organização. Precisa agir de forma ativa na adaptação, criação e desenvolvimento contínuo de seus processos, em vez de somente adaptar-se a reestruturações guiadas por empresas de consultoria. Isso porque o RH, à medida que conhecer melhor o negócio da empresa e o ambiente externo em que atua, poderá agir de forma ativa na definição de novos projetos e buscar desenvolvimento contínuo frente às constantes mudanças.

A reestruturação administrativa provocou a diminuição dos níveis hierárquicos e do quadro de pessoal ao mínimo possível. A aproximação das esferas de decisão e ação nos processos internos trouxe grandes mudanças, principalmente porque a Telebrás era uma empresa com vários níveis que tornavam o processo decisório lento. As decisões passaram a ser tomadas com agilidade, pois, segundo al guns entrevistados, os negócios em telecomunicações exigem respostas rápidas às mudanças externas e internas da empresa. Porém, a central ização das regras na matriz pode dificultar tal agilidade nas regionais frente às mudanças.

As decisões de maior relevância do RH passaram a ser discutidas em reuniões do comitê da Telemar. Se, 
de um lado, o RH passou a precisar da aprovação de outras áreas para a implementação de suas decisões, por outro, veio a intervir nessas áreas e direcionar suas ações para o resultado da empresa. Tal fato tornou 0 RH mais ativo e direcionou suas atividades ao negócio, proporcionando melhores resultados.

A nova estrutura centralizou as atividades de $\mathrm{RH}$ na matriz. Todos os processos, atividades, políticas e práticas foram redefinidos e repassados para as regionais. A adoção dessa estrutura repartiu os segmentos de investimentos da empresa em unidades de negócio e promoveu uma reestruturação organizacional. Muitas funções e cargos foram eliminados, e, diante disso, muitas pessoas acumularam funções e responsabilidades, tendo então possibilidades de ascensão e gratificações. Por outro lado, muitas pessoas foram demitidas, e o clima de insegurança quanto à permanência na empresa ainda existe, principalmente devido às mudanças contínuas e a falta de um plano de carreira que proporcione certa estabilidade e comprometimento do empregado com seu autodesenvolvimento. Essas mudanças permitiram o desenvolvimento, na matriz, de grupos polivalentes solucionadores de problemas, que evoluíram frente à centralização da antiga estrutura proporcionando resolução de problemas por caminhos mais dinâmicos com o uso de ferramentas avançadas.

A reestruturação que vem sendo implantada na empresa ainda não foi consolidada, mas apresenta resultados diferentes do que era praticado em 1998. Apesar de as práticas e políticas da GRH agora adotadas na Telemar não estarem total mente alinhadas ao modelo competitivo de gestão de pessoas proposto por Fischer (1998) e UIrich (1997), o resultado é positivo. Não se pode afirmar que o novo modelo implementado fará a empresa alcançar a meta de se tornar a maior empresa de telecomunicações por meio das pessoas devido à recente implantação do model o e à profundidade do assunto. Observa-se que a GRH evoluiu diante dos processos e políticas praticados em 1998, pois a gestão era limitada a processos de treinamentos locais, benefícios, assistência médica e rotinas de pessoal, e que alguns processos, práticas e políticas estão ainda sendo implementados e podem al cançar maiores resultados no futuro.

Todas as ações da Telemar, diante da reestruturação iniciada em 1999 com a empresa de consultoria, tinham como visão transformá-la na maior empresa de telecomunicações da América Latina até 2008. A
Tel emar obj etivava atingir essa meta por meio das pessoas, ou seja, por meio da gestão de seus Recursos Humanos.

\section{NOTAS}

\begin{abstract}
${ }^{1}$ Situação na economia de um país na qual a estagnação ou o declínio no nível de produção e emprego se combina com uma inflação acelerada (Sandroni, 1987).

2 "Empresas espelhos" é o nome pelo qual são tratadas as empresas que receberam autorização para explorar o serviço telefônico fixo, comutado nas áreas definidas pelo Plano Geral de Outorgas, concorrendo com as empresas originadas da privatização da Telebrás (Luz, 2001).
\end{abstract}

${ }^{3}$ Black belts lideram equipes na condução de projetos multifuncionais ou funcionais, alcançando maior visibilidade na estrutura Seis Sigma.

${ }^{4} \mathrm{G}$ reen belts são profissionais que participam das equipes lideradas pelos black belts (projetos multifuncionais ou funcionais) ou lideram equipes na condução de projetos funcionais.

\section{REFERÊNCIAS BIBLIOGRÁFICAS}

ALBU QUERQUE, L. G. 0 papel estratégico de recursos humanos. Tese (Livre-Docência) - FEA/USP, São Paulo, 1987.

BRANDÃO, C. B. Telecomunicações e dinâmica regional no Brasil. Tese (Doutorado em Administração) - Unicamp, São Paulo, 1996.

BURKE, W. W. What human resource practitioners need to know for the twenty-first century. Human Resource Management, v. 36, n. $1,1997$.

CALDAS, M. Enxugamento de pessoal no Brasil: pesquisa de campo comparativa sobre moderadores organizacionais dos efeitos de demissões coletivas em empresa e indivíduo. In: EN CONTRO NACIONAL DA ASSO CIAÇÃO DOS PROGRAMAS DE PÓS-GRADUAÇÃO E PESQUISA EM ADMINISTRAÇÃO, 22., Foz do I guaçu, 1998. Anais. Foz do Iguaçu: AN PAD, 1998.

DE BRUYNE, P.; HERMAN, J.; DE SCHOUTHEETE, M. Dinâmica da pesquisa em Ciências Sociais: os pólos da prática metodológica. Rio de Janeiro: Francisco Alves, 1997.

FLEURY, A.; FLEURY, M. T. L. Aprendizagem e inovação organizacional: as experiências do Japão, Coréia e Brasil. São Paulo: Fundação Vanzolini, 1995. 
FLEURY, M. T. L. Cultura da qualidade e mudança organizacional. Revista de Administração de Empresas, v. 33, n. 2, p. 26-34, 1993.

FISCHER, A. L. A constituição do modelo competitivo de gestão de pessoas no Brasil: um estudo sobre as empresas consideradas exemplares. Tese (Doutorado em Administração) - USP, São Paulo. 1998.

GODOY, A. S. Introdução à pesquisa e suas possibilidades. Revista de Administração de Empresas, v. 35, n. 2, p. 57-63, 1995.

GOODE, W. J.; HATT, P. K. M étodos em pesquisa social. São Paulo: Nacional, 1960.

GREENWOOD, E. Métodos principales de investigación social empírica. In: Metodología de la investigación social. Buenos Aires: Paidós, 1973.

LOPES, V. S. V. B. V. Impactos da privatização na gestão de pessoas: um estudo de caso em empresas do setor de transporte ferroviário de carga de Montes Claros - MG. Dissertação (Mestrado em Administração) - Cepead/FACE/UFMG, Belo Horizonte, 2000.

LUZ, T. R. Telemar-M inas: competências que marcam a diferença. Tese (Doutorado em Administração) - Cepead/ FACE/UFM G, Belo Horizonte, 2001.
MELO, M. C. O. Lopes. Revisão ou reconstrução do processo de gestão de pessoas da força de trabalho nas organizações - da ARH a gestão de pessoas? In: EN CONTRO NACIONAL DA ASSO CIAÇÃO DOS PROGRAMAS DE PÓS-GRADUAÇÃO E PESQUISA EM ADMINISTRAÇÃO, 21., 1997, Angra dos Reis. Anais. Rio de Janeiro: ANPAD, 1997.

SAN DRONI, P. Dicionário de economia. São Paulo: Best Seller, 1987.

SAVAS, E. S. A privatização: chave para um governo melhor. Rio de Janeiro: Nórdica, 1990.

TELEMAR, 2003. Disponível em <http://www.telemar.com.br>. Acesso em 10 jun. 2003.

ULRICH, D. Os campeões de recursos humanos: inovando para obter os melhores resultados. São Paulo: Futura, 1998.

ULRICH, Dave Judge me more by my future than by my past. Human Resource Management, v. 36, 1997.

WOOD JR. T. In: WOOD JR., T. (Org.). Mudança organizacional: aprofundando temas atuais em administração. São Paulo: Atlas, 1995.

\section{Artigo recebido em 23.08.2004. Aprovado em 18.07.2005.}

\section{Cláudia Santos de Castro}

Pesquisadora do Núcleo interdisciplinar sobre gestão em organizações não empresariais (Nig-one) da UFM G. Mestre em Administração pela UFM G-CEPEAD.

Interesses de pesquisa nas áreas de políticas, práticas e processos de recursos humanos e modernidade organizacional.

E-mail: claudia@cepead.face.ufmg.br

Endereço: Av. Petrolina 795, ap. 302, bl. 1, Sagrada Família, Belo Horizonte - M G, 31030-370. 